\title{
A NOVEL SIALYL LEWIS X ANALOG ATTENUATES CEREBRAL INJURY AFTER DEEP HYPOTHERMIC CIRCULATORY ARREST
}

Toshiharu Shin'oka, MD

Mitsugi Nagashima, MD

Georg Nollert, $\mathrm{MD}^{\mathrm{a}}$

Dominique Shum-Tim, MD, MSc ${ }^{\mathrm{a}}$

Peter C. Laussen, MBBS ${ }^{b}$

Hart G. W. Lidov, MD, $\mathrm{PhD}^{\mathrm{c}}$

Adre du Plessis, MD $^{\mathrm{d}}$

Richard A. Jonas, MDa
Background: The initial step in the inflammatory process, which can be initiated by cardiopulmonary bypass and by ischemia/reperfusion, is mediated by interactions between selectins on endothelial cells and on neutrophils. We studied the effects of selectin blockade using a novel Sialyl Lewis $\mathrm{X}$ analog (CY-1503) on recovery after deep hypothermic circulatory arrest in a piglet model. Methods: Twelve Yorkshire piglets were subjected to cardiopulmonary bypass, 30 minutes of cooling, 100 minutes of circulatory arrest at $15^{\circ} \mathrm{C}$, and 40 minutes of rewarming. Five animals received a bolus of $60 \mathrm{mg} / \mathrm{kg}$ of CY-1503 and an infusion (3 $\mathrm{mg} / \mathrm{kg}$ per hour) for 24 hours from reperfusion (group 0 ), and 7 randomly selected control piglets received saline solution (group C). Body weight and total body water content were evaluated 3 hours and 24 hours after reperfusion by a bio-impedance technique. Neurologic recovery of animals was evaluated daily by neurologic deficit score $(0=$ normal, 500 = brain death) and overall performance categories $(1=$ normal, 5 = brain death). The brain was fixed in situ on the fourth postoperative day and examined by histologic score $(0=$ normal, $5+=$ necrosis $)$ in a blinded fashion. Results: Two of 7 animals in group $\mathrm{C}$ died. The neurologic deficit score was significantly lower in group $\mathbf{O}$ than in group $\mathbf{C}$ (postoperative day $1, P<.001$; postoperative day $2, P=.02$ ). The overall performance category was significantly lower in group $\boldsymbol{O}$ than in group $\mathrm{C}$ on postoperative day $2(P=.01)$. Percentage total body water after cardiopulmonary bypass was significantly higher in group $\mathrm{C}$ than in group $\mathrm{O}(\boldsymbol{P}=\mathbf{. 0 3})$. Histologic score tended to be higher in group $\mathrm{C}$ than in group $O$, but this difference did not reach statistical significance (group $\mathrm{O}=0.5 \pm 0.7$; group $\mathrm{C}=1.3 \pm 1.9$ ). Conclusion: Blockade of selectin adhesion molecules by saturation with a Sialyl Lewis ${ }^{\mathrm{x}}$ analog accelerates recovery after 100 minutes of deep hypothermic circulatory arrest in a piglet survival model. (J Thorac Cardiovasc Surg 1999; 117:1204-11)
$\mathrm{N}$ eutrophil (PMN) adhesion to endothelium is important in mediating ischemia/reperfusion injury during and after cardiopulmonary bypass (CPB). Tethering and rolling of PMNs on activated endothelium is the initial step in the inflammatory process and is mediated by interactions between selectins on endothelial cells

From the Department of Cardiovascular Surgery, Children's Hospital, and Department of Surgery, Harvard Medical Schoola; the Department of Anesthesia and Intensive Care, Children's Hospital, and Department of Anesthesia, Harvard Medical School'b; the Department of Pathology, Children's Hospital, and Department of Pathology, Harvard Medical Schoolc; and the Department of Neurology, Children's Hospital, and Department of Neurology, Harvard Medical School, ${ }^{\mathrm{d}}$ Boston, Mass.

Received for publication Dec 4, 1998; revisions requested Jan 5, and specific oligosaccharides (Sialyl Lewis X: SLe ${ }^{\mathrm{x}}$ ) on PMNs. This may contribute to the no-reflow phenomenon, which has been demonstrated to be important in cerebral injury after reperfusion. Prevention of selectinmediated PMN adherence could potentially reduce PMN-mediated ischemia/reperfusion injury. The cur-

1999; revisions received Feb 2, 1999; accepted for publication Feb 9, 1999

Address for reprints: Richard A. Jonas, MD, Department of Cardiovascular Surgery, Children's Hospital, 300 Longwood Ave, Boston, MA 02115.

Copyright @ 1999 by Mosby, Inc.

$0022-5223 / 99 \$ 8.00+0 \quad \mathbf{1 2 / 1 / 9 7 7 7 0}$ 
rent study assessed the effect of selectin blockade using a specific synthetic oligosaccharide analog of $\mathrm{SLe}^{\mathrm{x}}$ (CY-1503) in 5-week-old piglets undergoing $100 \mathrm{~min}-$ utes of deep hypothermic circulatory arrest (DHCA) at $15^{\circ} \mathrm{C}$.

\section{Materials and methods}

Experimental preparation. All animals received humane care in compliance with the "Principles of Laboratory Animal Care" formulated by the National Society for Medical Research and the "Guide for the Care and Use of Laboratory Animals" prepared by the National Institutes of Health (NIH Publication No. 85-23, revised 1985).

Twelve 5-week-old Yorkshire pigs weighing 6.9 to $10.2 \mathrm{~kg}$ (mean $7.8 \mathrm{~kg}$ ) were anesthetized with intraperitoneal sodium methohexital $(45 \mathrm{mg} / \mathrm{kg}$ ) and intubated. Each animal's lungs were ventilated with an inspired oxygen fraction of 0.4 at a rate of 12 breaths/min with a pressure control ventilator (Healthdyne model 105; Healthdyne Technologies, Marietta, $\mathrm{Ga})$. After bolus injection of fentanyl $(25 \mu \mathrm{g} / \mathrm{kg})$ and pancuronium $(0.5 \mathrm{mg} / \mathrm{kg})$, anesthesia was maintained by continuous intravenous infusion of fentanyl ( $25 \mu \mathrm{g} / \mathrm{kg}$ per hour), midazolam $(0.2 \mathrm{mg} / \mathrm{kg}$ per hour $)$, and pancuronium $(0.2 \mathrm{mg} / \mathrm{kg}$ per hour) except during the circulatory arrest period. A brain temperature probe (model HH-71T, Cole-Parmer Instrument Co, Vernon Hills, Ill) was inserted into the subdural space through an 18-gauge needle hole and secured on the skin. Nasopharyngeal, rectal, and brain temperatures were recorded throughout the operation and in the postoperative period.

A catheter was placed into the superficial left femoral artery for continuous blood pressure monitoring and arterial blood gas sampling. The right femoral artery was exposed for the arterial cannula in preparation for $\mathrm{CPB}$. A right anterolateral thoracotomy was performed in the third intercostal space. The right atrium was exposed through the pericardium and prepared for venous cannulation.

After systemic heparinization (300 IU/kg), an $8 \mathrm{~F}$ arterial cannula and $24 \mathrm{~F}$ venous cannula were inserted into the right femoral artery and right atrium, respectively. CPB was then initiated and the animal was cooled to $15^{\circ} \mathrm{C}$ before $100 \mathrm{~min}$ utes of DHCA.

After 40 minutes of reperfusion and rewarming, CPB was discontinued, and the arterial and venous cannulas were removed when the animal's condition became stable. Protamine $(6 \mathrm{mg} / \mathrm{kg}$ ) was slowly administered intravenously. The chest was closed in layers with a $20 \mathrm{~F}$ chest tube left in place. Anesthesia was maintained for 12 hours. After the chest tube was removed, anesthesia was weaned and the animal extubated.

CPB technique. Details have been described previously. ${ }^{1}$ The pump prime consists of approximately $800 \mathrm{~mL}$ of electrolyte solution (Normosol R, pH 7.4; Abbott Laboratories, North Chicago, Ill) and $400 \mathrm{~mL}$ of homologous donor blood to achieve a hematocrit value of $20 \%$ during CPB. The prime is dosed with cefazolin sodium $(25 \mathrm{mg} / \mathrm{kg})$, methylprednisolone $(30 \mathrm{mg} / \mathrm{kg})$, furosemide $(0.25 \mathrm{mg} / \mathrm{kg})$, and sodium bicarbonate $(10 \mathrm{~mL})$.
Bypass flow was set at $100 \mathrm{~mL} / \mathrm{kg}$ per minute. The animal was immediately cooled to a nasopharyngeal temperature of $15^{\circ} \mathrm{C}$ and a rectal temperature of less than $18^{\circ} \mathrm{C}$ over 30 minutes by means of the $\mathrm{pH}$-stat strategy. Phentolamine $(0.2$ $\mathrm{mg} / \mathrm{kg}$ ) was administered before cooling. After 30 minutes of cooling, CPB was stopped for 100 minutes.

At a predetermined point for reperfusion, furosemide $(0.25$ $\mathrm{mg} / \mathrm{kg})$, mannitol $(0.5 \mathrm{~g} / \mathrm{kg})$, and sodium bicarbonate $(10 \mathrm{~mL})$ were administered to the pump. Reperfusion and rewarming were restarted at $100 \mathrm{~mL} / \mathrm{kg}$ per minute until a rectal temperature of $36^{\circ} \mathrm{C}$ was achieved and for at least 40 minutes. The heart was defibrillated as necessary at $25^{\circ} \mathrm{C}$ and blood was given to maintain a hematocrit value above $25 \%$. Ventilation was resumed 10 minutes before weaning from $\mathrm{CPB}$, with an intermittent mandatory ventilation rate of 16 to 18 breaths/min. The animal was then weaned from CPB.

Experimental groups. Five animals received CY-1503 (group O), and 7 randomly selected control piglets received saline solution (group C). In group $\mathrm{O}$, a bolus of $60 \mathrm{mg} / \mathrm{kg}$ was given in the pump prime and a continuous infusion of CY-1503 (3 mg/kg per hour) was started at the onset of reperfusion after circulatory arrest and ended 24 hours after the onset of CPB. In group $\mathrm{C}$, the same volume of saline solution was infused.

\section{Data collection}

1. Body weight change. Body weight was measured before anesthesia (baseline), 3 hours after CPB, on postoperative day (POD) 1, and on POD 4 and was expressed as percent of baseline measurement.

2. Total body water estimation by bio-electrical impedance. ${ }^{2}$ Total body water content was estimated by bio-electrical impedance (TBW 1/BEI) by means of the Weight Manager Analyzer (BIA-101Q; RJL Systems, Inc, Clinton Township, Mich). Percent change of total body water 3 hours after $\mathrm{CPB}$ was calculated using the baseline body weight before the operation.

3. Near-infrared spectroscopy. Details have been described previously. ${ }^{3}$ In brief, a pair of near-infrared spectroscopy fiberoptic optodes were attached to the head of the animal after induction of anesthesia. The optode spacing was $3.0 \mathrm{~cm}$ in a coronal plane. These optodes transmitted and detected laser light at near-infrared wavelengths and were connected to a near-infrared spectrometer (NIRO-500; Hamamatsu Photonics KK, Hamamatsu, Japan), which calculated relative concentration changes in oxygenated hemoglobin, deoxygenated hemoglobin, and oxidized cytochrome a,a3. These data were collected continuously after induction of anesthesia until 3 hours after the end of CPB.

4. Biochemical analysis. Blood samples were taken on the first postoperative day. Aspartate aminotransferase, alanine aminotransferase, lactate dehydrogenase, alkaline phosphatase, creatine kinase, and total bilirubin were measured.

5. Platelet count and white blood cell count. Blood samples were taken before and immediately after coming off CPB and on POD 1. Values were expressed as a percentage of baseline.

6. Neurologic and behavioral evaluations. ${ }^{4}$ Neurologic and behavioral evaluations were performed at 24-hour intervals 
Table I. Experimental conditions

\begin{tabular}{|c|c|c|c|}
\hline Group & $\begin{array}{c}\text { Group } C \\
(\text { mean } \pm S D)\end{array}$ & $\begin{array}{c}\text { Group } O \\
(\text { mean } \pm S D)\end{array}$ & $\begin{array}{c}\mathrm{t} \text { Test } \\
\mathrm{P} \text { value }\end{array}$ \\
\hline Body weight (kg) & $7.7 \pm 0.9$ & $7.9 \pm 1.5$ & .78 \\
\hline \multicolumn{4}{|l|}{ Hematocrit $(\%)$} \\
\hline Before operation & $25.4 \pm 2.9$ & $25.8 \pm 2.5$ & .78 \\
\hline Prime & $16.1 \pm 1.6$ & $16.6 \pm 1.1$ & .54 \\
\hline Before CA & $20.0 \pm 1.4$ & $19.8 \pm 1.3$ & .80 \\
\hline Before coming off $\mathrm{CPB}$ & $23.8 \pm 2.7$ & $24.0 \pm 2.3$ & .86 \\
\hline $3 \mathrm{~h}$ after $\mathrm{CPB}$ & $26.4 \pm 1.5$ & $27.2 \pm 1.9$ & .44 \\
\hline POD 1 & $30.9 \pm 3.9$ & $28.0 \pm 2.3$ & .12 \\
\hline \multicolumn{4}{|c|}{ Esophageal temperature $\left({ }^{\circ} \mathrm{C}\right)$} \\
\hline \multicolumn{4}{|l|}{ Cooling } \\
\hline $0 \min$ & $35.1 \pm 1.0$ & $34.6 \pm 1.8$ & .54 \\
\hline $30 \mathrm{~min}$ & $14.5 \pm 1.8$ & $13.1 \pm 1.8$ & .20 \\
\hline \multicolumn{4}{|l|}{ Rewarming } \\
\hline $0 \mathrm{~min}$ & $16.0 \pm 2.8$ & $17.5 \pm 2.0$ & .27 \\
\hline $40 \mathrm{~min}$ & $35.7 \pm 1.7$ & $36.9 \pm 1.3$ & .16 \\
\hline \multicolumn{4}{|l|}{ Rectal temperature $\left({ }^{\circ} \mathrm{C}\right)$} \\
\hline \multicolumn{4}{|l|}{ Cooling } \\
\hline $0 \mathrm{~min}$ & $34.7 \pm 0.9$ & $35.9 \pm 0.9$ & .04 \\
\hline $30 \mathrm{~min}$ & $17.2 \pm 3.1$ & $18.0 \pm 1.8$ & .54 \\
\hline \multicolumn{4}{|l|}{ Rewarming } \\
\hline $0 \mathrm{~min}$ & $19.5 \pm 2.6$ & $17.1 \pm 2.9$ & .18 \\
\hline $40 \mathrm{~min}$ & $34.8 \pm 0.6$ & $35.8 \pm 0.9$ & .09 \\
\hline \multicolumn{4}{|l|}{ Brain temperature $\left({ }^{\circ} \mathrm{C}\right)$} \\
\hline Before CPB & $36.9 \pm 0.4$ & $37.1 \pm 1.3$ & .75 \\
\hline \multicolumn{4}{|l|}{ Cooling } \\
\hline $0 \mathrm{~min}$ & $34.2 \pm 3.7$ & $36.1 \pm 2.6$ & .30 \\
\hline $30 \mathrm{~min}$ & $16.0 \pm 2.2$ & $16.0 \pm 3.6$ & .99 \\
\hline \multicolumn{4}{|l|}{ Rewarming } \\
\hline $0 \mathrm{~min}$ & $16.4 \pm 2.0$ & $16.0 \pm 2.2$ & .27 \\
\hline $40 \mathrm{~min}$ & $37.3 \pm 1.4$ & $37.6 \pm 1.7$ & .74 \\
\hline \multicolumn{4}{|l|}{ After CPB } \\
\hline $1 \mathrm{~h}$ & $35.5 \pm 1.3$ & $37.1 \pm 1.5$ & .09 \\
\hline $2 \mathrm{~h}$ & $36.6 \pm 1.4$ & $37.5 \pm 1.0$ & .22 \\
\hline $3 \mathrm{~h}$ & $37.0 \pm 0.9$ & $37.2 \pm 0.6$ & .58 \\
\hline $4 \mathrm{~h}$ & $36.7 \pm 0.4$ & $36.9 \pm 1.5$ & .77 \\
\hline $5 \mathrm{~h}$ & $36.9 \pm 0.4$ & $36.2 \pm 1.5$ & .40 \\
\hline $6 \mathrm{~h}$ & $37.0 \pm 0.6$ & $36.8 \pm 1.2$ & .76 \\
\hline $8 \mathrm{~h}$ & $37.2 \pm 0.6$ & $36.9 \pm 1.1$ & .52 \\
\hline $10 \mathrm{~h}$ & $37.3 \pm 0.9$ & $37.0 \pm 1.0$ & .62 \\
\hline $12 \mathrm{~h}$ & $37.6 \pm 0.9$ & $37.4 \pm 1.5$ & .77 \\
\hline $24 \mathrm{~h}$ & $39.2 \pm 1.1$ & $38.0 \pm 0.9$ & .09 \\
\hline $36 \mathrm{~h}$ & $39.2 \pm 0.5$ & $38.1 \pm 0.9$ & .06 \\
\hline $48 \mathrm{~h}$ & $39.1 \pm 0.5$ & $38.2 \pm 1.2$ & .19 \\
\hline $72 \mathrm{~h}$ & $39.0 \pm 0.4$ & $38.6 \pm 0.4$ & .17 \\
\hline $96 \mathrm{~h}$ & $39.0 \pm 0.5$ & $38.8 \pm 0.7$ & .65 \\
\hline \multicolumn{4}{|c|}{ Perfusion pressure $(\mathrm{mm} \mathrm{Hg})$} \\
\hline \multicolumn{4}{|l|}{ Cooling } \\
\hline $10 \mathrm{~min}$ & $58.4 \pm 20.3$ & $44.2 \pm 4.0$ & .09 \\
\hline $20 \mathrm{~min}$ & $52.8 \pm 15.2$ & $40.2 \pm 6.8$ & .07 \\
\hline $30 \mathrm{~min}$ & $49.3 \pm 14.6$ & $42.0 \pm 8.0$ & .27 \\
\hline \multicolumn{4}{|l|}{ Rewarming } \\
\hline $10 \mathrm{~min}$ & $54.4 \pm 15.2$ & $48.0 \pm 5.6$ & .31 \\
\hline $20 \mathrm{~min}$ & $78.3 \pm 30.6$ & $69.4 \pm 22.0$ & .56 \\
\hline $30 \mathrm{~min}$ & $83.1 \pm 24.6$ & $76.0 \pm 22.2$ & .60 \\
\hline $40 \mathrm{~min}$ & $79.1 \pm 23.8$ & $73.8 \pm 19.1$ & .67 \\
\hline
\end{tabular}

$S D$, Standard deviation; $C A$, circulatory arrest; $C P B$, cardiopulmonary bypass; $P O D$, postoperative day. by observers blinded to the protocol, as described previously in detail. ${ }^{4}$ Neurologic deficit score (NDS) and overall performance category (OPC) were modified and used for the evaluation of animal recovery. In the NDS system, a score of 100 is assigned to each of 5 general components (central nervous system function, respiration, motor and sensory function, level of consciousness, and behavior). A total score of 500 indicates brain death, and a score of 0 is normal. The OPC system establishes neurobehavioral criteria for 5 categories from 1 to 5 : $1=$ normal, $2=$ moderate disability, $3=$ severe disability, $4=$ coma, and $5=$ brain death.

7. Histologic evaluations. Details have been described previously. ${ }^{4}$

8. Drug concentration. Blood samples were taken from the pump prime and animals during $\mathrm{CPB}$ and at 1, 6, 7, 12, and 24 hours after CPB. Three milliliters of blood was drawn for each sample and placed into a Vacutainer tube (Becton Dickinson Vacutainer Systems, Franklin Lakes, NJ) containing sodium heparin preservative. The blood was mixed and kept on ice after initial sampling. The samples were centrifuged immediately for 15 minutes at $2000 \mathrm{rpm}$. The serum was then transferred to polypropylene tubes and frozen at $-70^{\circ} \mathrm{C}$ for further analysis.

Statistical analysis. All results were expressed as mean \pm standard deviation of the mean and analyzed by a statistical analysis software package (StatView version 4.5, Abacus Concepts, Inc, Berkeley, Calif). The unpaired $t$ test was used.

\section{Results}

Experimental conditions (Table I). No differences were found in body weight and hematocrit value during $\mathrm{CPB}$ and on POD 1 between groups. There were no statistically significant differences in nasopharyngeal, rectal, and brain temperatures during the cooling and rewarming phases. There were no statistically significant differences in brain temperature up to POD 4 between groups, although brain temperature tended to be higher in group $\mathrm{C}$ than group $\mathrm{O}$. There were no significant differences in perfusion pressure during cooling between the 2 groups, although pressure tended to be lower in group $\mathrm{O}$.

Operative results. Two of 7 animals in group $\mathrm{C}$ died on PODs 1 and 2 as a result of arrhythmias caused by heart failure. All data from these animals were excluded from subsequent analysis. All other animals were extubated within 18 hours of the operation and survived for 4 days after the operation until put to death for histologic examination.

Body weight change (Table II). Three hours after $\mathrm{CPB}$, body weight gain was significantly lower in group $\mathrm{O}$ than in group $\mathrm{C}$. On PODs 1 and 4 there were no significant differences between groups.

Total body water content by bio-electrical impedance (Table II). Calculated percentage total body water 
content 3 hours after CPB was significantly lower in group $\mathrm{O}$.

Near-infrared spectroscopy (Fig 1, A, B, and $C$ ). The oxygenated hemoglobin signal increased significantly during cooling in both groups. From the onset of DHCA, there was a decline in oxygenated hemoglobin and cytochrome a,a3 signals in both groups, whereas deoxygenated hemoglobin increased reciprocally (Fig 1). During DHCA and after CPB, cytochrome a,a3 recovery tended to be higher in group $\mathrm{O}$ than in group C. However, 3 hours after CPB there were no differences between groups.

Enzymes (Table II). There was a statistically significant difference in creatine kinase leakage on POD 1 between groups, with the level being lower with group O. Levels of aspartate aminotransferase, alanine aminotransferase, lactate dehydrogenase, and total bilirubin tended to be lower in group $\mathrm{O}$, although no significant differences were observed.

Platelet count and white blood cell count analysis (Table II). Percentage platelet count was significantly higher in group $\mathrm{O}$ just after coming off $\mathrm{CPB}$. However, there was no statistically significant difference in percent white blood cell count between groups.

NDS (Table II, Fig 2, $A$ and $B$ ). The NDS and OPC demonstrated more rapid recovery in group $\mathrm{O}$ than in group C. On POD 2, both the NDS and OPC score in group $\mathrm{O}$ were significantly better than in group $\mathrm{C}$. On PODs 1 and 3, NDSs were better in group O. By POD 4 , almost all animals showed normal recovery neurologically.

Neuropathologic results. Neuropathologic damage was evaluated, as in previous studies, primarily by the presence of hypereosinophilic shrunken neurons with karyorrhectic nuclei. This feature is evidence of recent hypoxic ischemic injury. The hypoxic/ischemic injury was more pronounced in group $\mathrm{C}$, although the degree of injury even in this control group of animals was quite mild. Negligible injury was observed in group $\mathrm{O}$, although the differences between group $\mathrm{O}$ and group $\mathrm{C}$ did not achieve statistical significance.

Drug concentration (Fig 3). In the pump prime the initial concentration of CY-1503 was $648 \pm 13 \mu \mathrm{g} / \mathrm{mL}$. It decreased immediately after the onset of CPB to $197 \pm 5$ $\mu \mathrm{g} / \mathrm{mL}$ owing to hemodilution, and it decreased gradually during CPB. After the animal was weaned from CPB, the concentration of CY- 1503 was consistently stable at 30 to $50 \mu \mathrm{g} / \mathrm{mL}$ up to 24 hours after reperfusion.

\section{Discussion}

This study has shown that the administration of CY1503 accelerates neurologic recovery after 100 minutes
Table II. Results

\begin{tabular}{|c|c|c|c|}
\hline & $\begin{array}{c}\text { Group C } \\
(\text { mean } \pm S D)\end{array}$ & $\begin{array}{c}\text { Group } O \\
(\text { mean } \pm S D)\end{array}$ & $\begin{array}{c}\mathrm{t} \text { Test } \\
\mathrm{P} \text { value }\end{array}$ \\
\hline \multicolumn{4}{|c|}{ Percent body weight } \\
\hline After CPB & $115.5 \pm 3.1$ & $111.0 \pm 1.4$ & $.04 *$ \\
\hline POD 1 & $109.4 \pm 4.3$ & $109.0 \pm 2.8$ & .84 \\
\hline POD 4 & $101.5 \pm 8.0$ & $107.0 \pm 11.6$ & .41 \\
\hline \multicolumn{4}{|c|}{ Percent total body water } \\
\hline After CPB & $123.2 \pm 12.8$ & $106.7 \pm 1.6$ & $.03 *$ \\
\hline POD 1 & $121.5 \pm 13.6$ & $120.6 \pm 5.7$ & .60 \\
\hline \multicolumn{4}{|l|}{ Neurologic score } \\
\hline \multicolumn{4}{|l|}{ NDS } \\
\hline POD 1 & $214.3 \pm 25.1$ & $153.0 \pm 20.8$ & $.00^{*}$ \\
\hline POD 2 & $105.0 \pm 45.6$ & $45.0 \pm 17.3$ & $.02 *$ \\
\hline POD 3 & $36.7 \pm 19.4$ & $5.0 \pm 7.1$ & $.01 *$ \\
\hline POD 4 & $12.5 \pm 14.7$ & $0.0 \pm 0.0$ & .09 \\
\hline \multicolumn{4}{|l|}{ OPC } \\
\hline POD 1 & $3.3 \pm 0.5$ & $3.0 \pm 0.0$ & .17 \\
\hline POD 2 & $2.5 \pm 0.5$ & $1.4 \pm 0.5$ & $.01^{*}$ \\
\hline POD 3 & $1.5 \pm 0.8$ & $1.0 \pm 0.0$ & .20 \\
\hline POD 4 & $1.2 \pm 0.4$ & $1.0 \pm 0.0$ & .36 \\
\hline \multicolumn{4}{|l|}{ Enzyme } \\
\hline AST & $153.7 \pm 36.7$ & $111.0 \pm 37.8$ & .45 \\
\hline ALT & $30.9 \pm 4.2$ & $18.2 \pm 14.7$ & .51 \\
\hline LDH & $1,349.0 \pm 471.7$ & $1,019.2 \pm 252.1$ & .15 \\
\hline ALP & $194.6 \pm 40.3$ & $189.8 \pm 26.1$ & .81 \\
\hline CK & $3,927.7 \pm 1807.9$ & $1,865.8 \pm 499.7$ & $.02 *$ \\
\hline Total bilirubin & $0.5 \pm 0.4$ & $0.2 \pm 0.1$ & .07 \\
\hline BUN & $18.7 \pm 7.7$ & $16.8 \pm 2.8$ & .56 \\
\hline \multicolumn{4}{|l|}{ Lactate } \\
\hline After CPB & $6.9 \pm 1.9$ & $5.9 \pm 0.8$ & .21 \\
\hline $24 \mathrm{~h}$ after $\mathrm{CPB}$ & $2.4 \pm 0.5$ & $2.0 \pm 0.6$ & .31 \\
\hline \multicolumn{4}{|l|}{$\mathrm{SvO}_{2}(\%)$} \\
\hline After CPB & $78.0 \pm 10.5$ & $88.5 \pm 2.1$ & .06 \\
\hline $24 \mathrm{~h}$ after CPB & $76.9 \pm 4.5$ & $83.0 \pm 4.1$ & .07 \\
\hline WBC baseline & $18,600 \pm 4,150$ & $18,400 \pm 2,480$ & .95 \\
\hline \multicolumn{4}{|l|}{ Percent WBC } \\
\hline After CPB & $78.2 \pm 40.0$ & $98.3 \pm 65.6$ & .56 \\
\hline $24 \mathrm{~h}$ after CPB & $157.9 \pm 81.6$ & $164.7 \pm 52.4$ & .86 \\
\hline Platelet baseline & $6,250,000 \pm 82,000$ & $5,640,000 \pm 61,000$ & .17 \\
\hline \multicolumn{4}{|l|}{ Percent platelet } \\
\hline After CPB & $48.5 \pm 9.8$ & $68.2 \pm 9.5$ & $.01^{*}$ \\
\hline $24 \mathrm{~h}$ after CPB & $60.1 \pm 18.6$ & $80.2 \pm 49.7$ & .43 \\
\hline
\end{tabular}

$S D$, Standard deviation; $C P B$, cardiopulmonary bypass; $P O D$, postoperative day; $N D S$, neurologic deficit score; $O P C$, overall performance category; $A S T$, aspartate aminotransferase; $A L T$, alanine aminotransferase; $L D H$, lactate dehydrogenase; $A L P$, alkaline phosphatase; $C K$, creatine kinase; $B U N$, blood urea nitrogen; SVO2, venous oxygen saturation; $W B C$, white blood cells. $* P<.05$.

of DHCA in a piglet model, although histologic examination did not confirm significant improvement in protection of neural parenchymal tissue. This is perhaps not surprising, because the sample size was small, control group histologic damage was not great, and the observation period was limited. However, this study did demonstrate evidence of possible blockade of platelet adhesion to either endothelial cells or the pump 

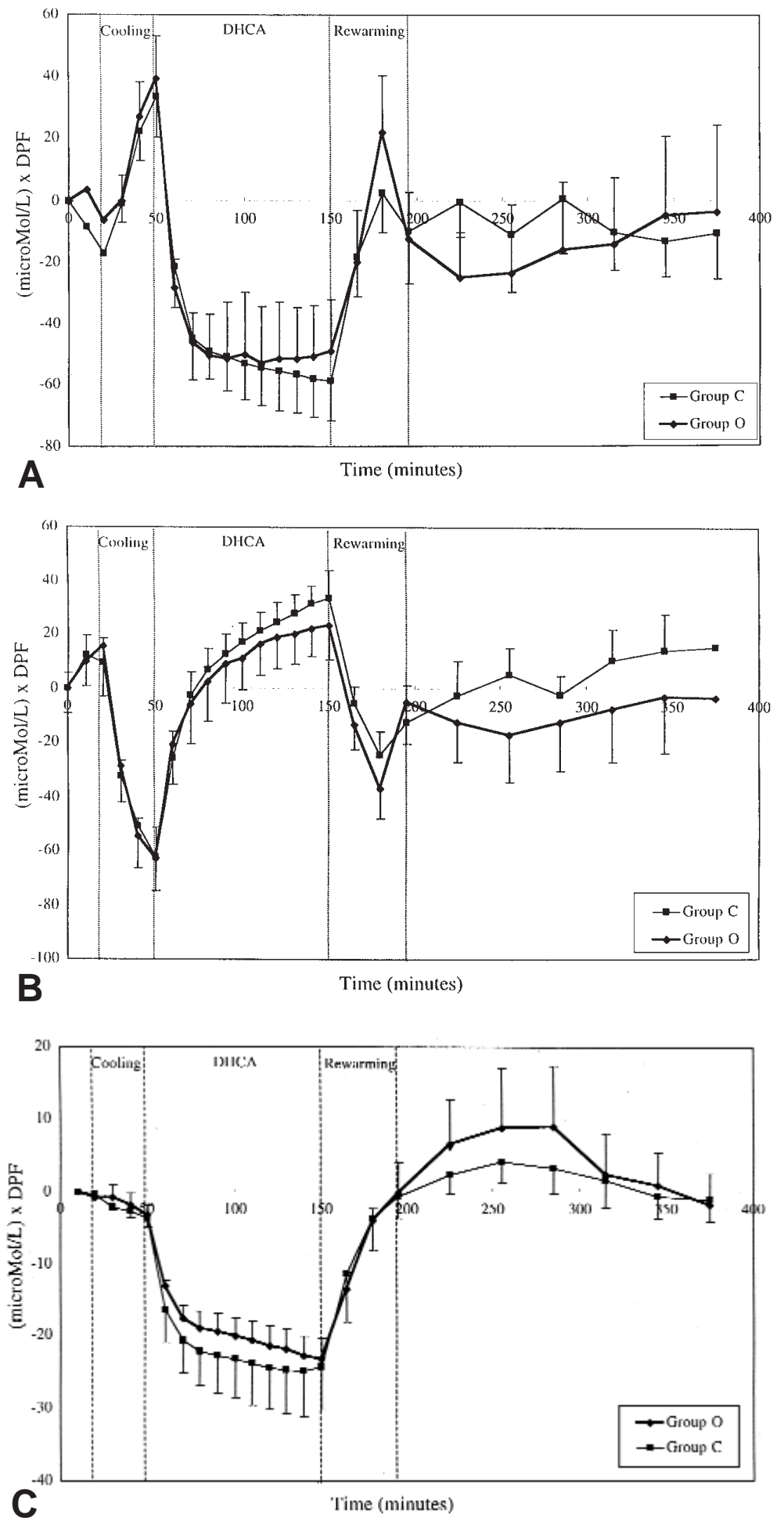

Fig 1. Near-infrared spectroscopy. A, Changes in oxygenated hemoglobin. B, Changes in deoxygenated hemoglobin. $\mathbf{C}$, Changes in cytochrome a,a3. DHCA, Deep hypothermic circulatory arrest; microMol/L) $\times$ DPF, micromolar $\times$ differential pathlength factor.

circuit during $\mathrm{CPB}$, reduction of edema, creatine kinase leakage, and improvement in neurologic performance after CPB. Regarding neurologic and behavioral evalu- ations, NDS is more discriminatory than OPC, which may explain the greater significance observed in NDS (Table II). Percentage platelet count immediately after 
$\mathrm{CPB}$ in group $\mathrm{O}$ demonstrated more free platelets and, by inference, less platelet adhesion during CPB, which may potentially increase the risk of bleeding after cardiac surgery.

After CPB and DHCA, a "whole body inflammatory response" occurs because of the summation of a number of initiating factors triggered by ischemia. These include endothelial dysfunction, white blood cell activation caused by exposure to the extracorporeal circuit, and the release of a myriad of inflammatory mediators such as interleukins, thromboxanes, histamine, complement, and kallikrein. During reperfusion, this inflammatory state begins to manifest itself, for example, as interstitial fluid accumulation and whole body edema. It is speculated that PMNs play a pivotal role in the events leading to reperfusion injury. The first step involves margination of the activated PMNs during laminar flow, followed by a loose, transient adhesion to the vascular endothelial cell surface known as "rolling." The next step in this sequence is a firmer adhesion or "sticking" of the PMNs and, finally, transmigration of these cells through the vessel wall. Once in the parenchymal tissue, PMNs exert their destructive effects through the release of proteolytic enzymes (eg, elastases and collagenases), chemotactic agents (eg, thromboxane $\mathrm{A}_{2}$ ), oxygen-derived free radicals (eg, superoxide, myeloperoxidase, and hydrogen peroxide), and other agents. 5,6

The selectin family of glycoproteins has been found to mediate PMN "rolling," which is a prerequisite step for the subsequent firmer adhesion. ${ }^{7}$ P-selectin and Eselectin are both found on the surface of activated endothelial cells, whereas only P-selectin is usually expressed on platelets. L-selectin, on the other hand, is constitutively expressed mainly on PMNs. The ligand for the L-selectin on leukocytes is thought to be a similar oligosaccharide, although it is not completely characterized. ${ }^{8,9}$ As previously mentioned, endothelial dysfunction occurs as a result of CPB/DHCA. One of the characteristic features of endothelial dysfunction is the expression of P-selectin. The mechanism that underlies this process is extrusion of this pre-formed glycoprotein from within Weibel-Palade bodies onto the cell surface. ${ }^{10}$ Once reperfusion is commenced, activated PMNs come into close apposition with the endothelial surface, and adhesion occurs through the recognition of a common ligand, known as SLe ${ }^{\mathrm{x}}$, which is abundantly expressed on the surface glycoproteins of PMNs and serves as the ligand for the 2 adhesion molecules Eselectin and P-selectin. Neither E-selectin nor Pselectin is found on resting vascular endothelial cells.

$\mathrm{SLe}^{\mathrm{x}}$ is a tetrasaccharide that contains essential residues sialic acid and fucose. ${ }^{11-14}$ It is known that $\mathrm{P}$ selectin binds to L-selectin-bound $\mathrm{SLe}^{\mathrm{x}}$ during reper-
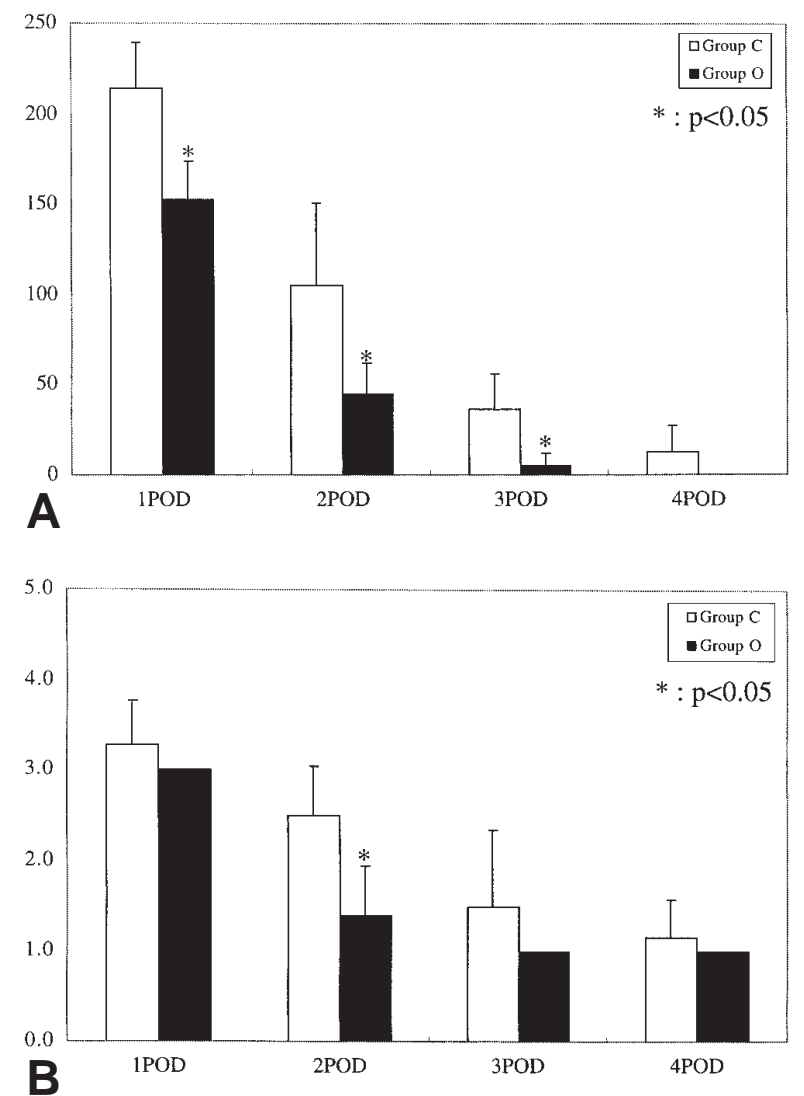

Fig 2. A, Neurologic deficit scores. B, Overall performance categories. All animals had same values on postoperative days 1,3 , and 4 (1POD, 3POD, 4POD). $* P<.05$ versus group C.

fusion injury, whereas the roles of E-selectin are unclear, because it is expressed only 4 to 6 hours after cell activation. ${ }^{15,16}$

CY-1503 is a synthetic pentasaccharide that contains $\mathrm{SLe}^{\mathrm{x}}$ ligand. It was developed in an effort to block PMN interaction competitively with both E-selectin and Pselectin expressed on the surface of endothelial cells. ${ }^{17}$

Several in vivo reports have already shown the beneficial effects of CY-1503 against ischemia/reperfusion injury. In 1994 Lefer and associates ${ }^{18}$ first demonstrated strong evidence that treatment with a unique carbohydrate analog of SLe ${ }^{\mathrm{x}}, \mathrm{CY}-1503(5 \mathrm{mg} / \mathrm{kg}$, intravenously), significantly reduced the PMN accumulation and the degree of myocardial injury associated with 90 minutes of occlusion of the left circumflex coronary artery and 4.5 hours of reperfusion in a dog model. They also measured plasma levels of CY-1503 using high $\mathrm{pH}$ anion exchange chromatography and indicated that $\mathrm{SLe}^{\mathrm{x}}$ is rapidly metabolized. Plasma level of CY1503 was $7.9 \pm 0.5 \mu \mathrm{g} / \mathrm{mL}$ at 60 minutes of reperfusion. The level declined to $3.4 \pm 1.0 \mu \mathrm{g} / \mathrm{mL}$ at 120 minutes 


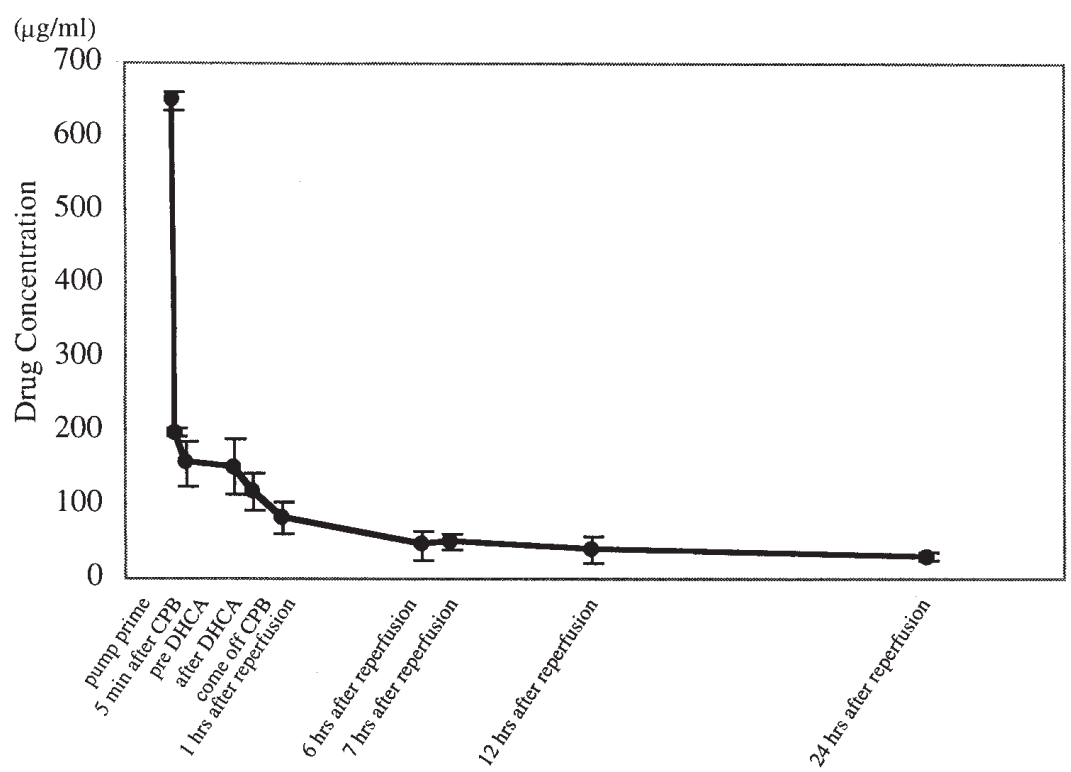

Fig 3. CY-1503 concentration in blood over time. $C P B$, Cardiopulmonary bypass; $D H C A$, deep hypothermic circulatory arrest.

of reperfusion, and they could not detect any trace of this substance after 180 minutes of reperfusion. ${ }^{18}$ Silver and coworkers ${ }^{19}$ also reported successful reduction of infarct size beyond thrombolysis in the canine model of an electrolytically thrombosed coronary artery using a bolus of CY-1503 $(40 \mathrm{mg} / \mathrm{kg})$ and infusion of tissue-type plasminogen activator $(20 \mathrm{mg} / \mathrm{kg}$ per minute). However, it is not clear from these shortterm studies whether CY-1503 treatment merely delayed the onset or actually reduced the full extent of myocardial necrosis after ischemia and reperfusion. Gill, Kong, and Horwitz ${ }^{20}$ used a model similar to Lefer's to examine the effects of CY-1503 in an acute canine model of myocardial ischemia and reperfusion. Dogs were subjected to 90 minutes of ischemia through occlusion of the left anterior descending coronary artery and 48 hours of reperfusion. Five minutes before the onset of reperfusion, dogs received CY-1503 at a dose of $20 \mathrm{mg} / \mathrm{kg}$. Unlike the previous reports, these authors did not find any beneficial effects of CY-1503 in reducing myocardial infarct size nor cardiac myeloperoxidase activity, although this may have been because of an inadequate dose. ${ }^{21}$ They hypothesized that CY-1503 might effectively block P-selectin binding but not the later expression of E-selectin. ${ }^{20}$

Several other ischemia/reperfusion injury models have been developed to examine the effects of CY-1503. Misawa and coworkers ${ }^{22}$ demonstrated significant improvement in biochemical evidence of hepatic injury after 90 minutes of total hepatic ischemia in a rat model when they administered a $25 \mathrm{mg} / \mathrm{kg}$ dose of CY-1503 5 minutes before reperfusion. They also showed a significant difference in myeloperoxidase and degree of necrosis in hepatic tissue 6 hours after reperfusion. Han and associate ${ }^{23}$ demonstrated that $\mathrm{CY}-1503$ attenuated reperfusion injury in the rabbit ear. They concluded that CY-1503 was efficacious only if administered in the first hour after reperfusion, suggesting that the more immediately available P-selectin and L-selectin participated in the PMN adhesion/injury process, whereas Eselectin, with its delayed endothelial expression, did not. On the other hand, Zhang and colleagues ${ }^{24}$ showed evidence of the involvement of E-selectin in transient major coronary artery occlusion in rats and suggested that E-selectin might facilitate PMN adhesion and subsequent cerebral ischemic cell damage.

The mechanism of protection during ischemia/reperfusion of exogenous SLe ${ }^{\mathrm{x}}$ has not been well described. It is possible that this compound, after ischemia/reperfusion injury, might compete with the binding of the naturally occurring (endogenous) product in the PMNs, to the expressed selectins receptor in the endothelium or platelet. This may result in less adhesion and infiltration of PMNs with subsequent diminished tissue damage. Another possibility is that CY-1503 might block platelet/PMN adhesion and decrease the production of PMN/platelet complexes that may be a cause of the no-flow phenomenon after ischemia/reperfusion. 
Near-infrared spectroscopy in our study suggests a trend toward improved cytochrome oxygenation in the group receiving CY-1503. However, beyond the immediate rewarming phase there is a trend toward less oxygenated hemoglobin and less deoxygenated hemoglobin in the CY-1503 group, which does not support the hypothesis that cytochrome oxygenation is improved by increased cerebral blood flow. CY-1503 was associated with less whole body edema after CPB, suggesting that the whole body inflammatory response was indeed reduced. Fluid shifts per se might explain the more rapid neurologic and behavioral recovery observed with CY-1503 and is consistent with the absence of a difference in histology between the treated and untreated groups. The importance of edema in influencing the behavioral recovery is also supported by the absence of a statistical difference in the near-infrared spectroscopy findings between the 2 groups.

In conclusion, the analog of SLe ${ }^{\mathrm{x}}$ CY-1503 attenuates whole body injury after 100 minutes of DHCA at $15^{\circ} \mathrm{C}$ in 5-week-old piglets.

We thank Mark A. Cioffi and Gene Walter for technical assistance, Laura Young for preparation of the manuscript, and Jane Newburger, MD, for her suggestions and guidance. CY-1503 used in this study was donated by Cytel Corporation, San Diego, California.

\section{REFERENCES}

1. Shin'oka T, Shum-Tim D, Jonas RA, Lidov HGW, Laussen PC, Miura T, et al. Higher hematocrit improves cerebral outcome after deep hypothermic circulatory arrest. J Thorac Cardiovasc Surg 1996;112:1610-21.

2. Maehara T, Novak I, Wyse RKH, Elliott MJ. Perioperative monitoring of total body water by bio-electrical impedance in children undergoing open heart surgery. Eur J Card Surg 1991;5:258-64.

3. Hiramatsu T, Miura T, Forbess JM, Du Plessis A, Cioffi MA, Aoki $\mathrm{M}$, et al. pH Strategy and cerebral energetics before and after circulatory arrest. J Thorac Cardiovasc Surg 1995;109:948-58.

4. Forbess JM, Ibla JC, Lidov H, Cioffi M, Hiramatsu T, Laussen P, et al. University of Wisconsin cerebroplegia in a piglet survival model of circulatory arrest. Ann Thorac Surg 1995;60:S494-500.

5. Levy JH, Kelly AB. Inflammation and cardiopulmonary bypass. Can J Anaesth 1993;40:1009-15.

6. Edmunds LH. Inflammatory and immunological response to cardiopulmonary bypass. In: Jonas RA, Elliott MJ, editors. Cardiopulmonary bypass in neonate, infants and young children. Oxford: Butterworth-Heinemann Ltd; 1994. p. 225-41.

7. Lefer AM. Role of selectins in myocardial ischemia-reperfusion injury. Ann Thorac Surg 1995;60:773-7.

8. Majuri ML, Pinola M, Niemela R, Tiisala S, Natunen J, Renkonen $\mathrm{O}$, et al. Alpha 2,3-sialyl and alpha 1,3-fucosyltransferase-dependent synthesis of sialyl Lewis $\mathrm{x}$, an essential oligosaccharide present on L-selectin counterreceptors, in cultured endothelial cells. Eur J Immunol 1994;24:3205-10.

9. Carlos TM, Harlan JM. Leukocyte-endothelial adhesion molecules. Blood 1994;84:2068-101.

10. Gill EA, Kong Y, Horwitz LD. An oligosaccharide sialylLewis(x) analogue does not reduce myocardial infarct size after ischemia and reperfusion in dogs. Circulation 1996;94:542-6.

11. Altavilla D, Squadrito F, Ioculano M, Canale P, Campo GM, Zingarelli B, et al. E-selectin in the pathogenesis of experimental myocardial ischemia-reperfusion injury. Eur $\mathrm{J}$ Pharmacol 1994;270:45-51

12. Lowe JB, Stoolman LM, Nair RP, Larsen RD, Berhend TL, Marks RM. ELAM-1-dependent cell adhesion to vascular endothelium determined by a transfected human fucosyltransferase cDNA. Cell 1990;63:475-84.

13. Phillips ML, Nudelman E, Gaeta FC, Perez M, Singhal AK, Hakomori S, et al. ELAM-1 mediates cell adhesion by recognition of a carbohydrate ligand, sialyl-Lex. Science 1990;250: 1130-2.

14. Foxall C, Watson SR, Dowbenko D, Fennie C, Lasky LA, Kiso $\mathrm{M}$, et al. The three members of the selectin receptor family recognize a common carbohydrate epitope, the sialyl Lewis(x) oligosaccharide. J Cell Biol 1992;117:895-902.

15. Walz G, Aruffo A, Kolanus W, Bevilacqua M, Seed B. Recognition by ELAM-1 of the sialyl-Lex determinant on myeloid and tumor cells. Science 1990;250:1132-5.

16. Polley MJ, Phillips ML, Wayner E, Nudelman E, Singhal AK, Hakomori S, et al. CD62 and endothelial cell-leukocyte adhesion molecule 1 (ELAM-1) recognize the same carbohydrate ligand, sialyl-Lewis x. Proc Natl Acad Sci U S A 1991;88:6224-8.

17. Picker LJ, Warnock RA, Burns AR, Doerschuk CM, Berg EL, Butcher EC. The neutrophil selectin LECAM-1 presents carbohydrate ligands to the vascular selectins ELAM-1 and GMP-140. Cell 1991;66:921-33.

18. Lefer DJ, Flynn DM, Phillips ML, Ratcliffe M, Buda AJ. A novel sialyl LewisX analog attenuates neutrophil accumulation and myocardial necrosis after ischemia and reperfusion. Circulation 1994;90:2390-401.

19. Silver MJ, Sutton JM, Hook S, Lee P, Malycky JL, Phillips ML, et al. Adjunctive selectin blockade successfully reduces infarct size beyond thrombolysis in the electrolytic canine coronary artery model. Circulation 1995;92:492-9.

20. Gill EA, Kong Y, Horwitz LD. An oligosaccharide sialyl-Lewisx analogue does not reduce myocardial infarct size after ischemia and reperfusion in dogs. Circulation 1996;94:543-6.

21. Flynn DM, Buda AJ, Jeffords PR, Lefer DJ. A sialyl Lewis (x)containing carbohydrate reduces infarct size: role of selectins in myocardial reperfusion injury. Am J Physiol 1996;271: H2086-96.

22. Misawa K, Toledo-Pereyra LH, Phillips ML, Garcia-Cirado FJ, Lopez-Neblina F, Paez-Rollys A. Role of sialyl Lewis(x) in total hepatic ischemia and reperfusion. J Am Coll Surg 1996;182:251-6.

23. Han KT, Sharar SR, Phillips ML, Harlan JM, Winn RK. Sialyl Lewis $(\mathrm{x})$ oligosaccharide reduces ischemia-reperfusion injury in the rabbit ear. J Immunol 1995;155:4011-5.

24. Zhang RL, Chopp M, Zhang ZG, Phillips ML, Rosenbloom CL, Cruz R, et al. E-selectin in focal cerebral ischemia and reperfusion in the rat. J Cereb Blood Flow Metab 1996;16:1126-36. 